\title{
Impact of financial background and student debt on postgraduate residency choices of medical students in Singapore
}

\author{
Jie Ming Nigel Fong ${ }^{1}$, MBBs(Hons), Yeong Tze Wilnard $\underline{T a n}^{2}$, MBBS, Andrew Arjun Sayampanathan ${ }^{1}$, MBBS, \\ Niraj Mohan ${ }^{3}$, Yun Qing Koh ${ }^{3}$, Jin Hao Justin Jang ${ }^{3}$, Jin Rong Ivan Low ${ }^{3}$, Anupama Vasudevan ${ }^{4}$, BDS, PhD, \\ Chew Lip $\underline{N g}^{3}$, MBBS, MRCSEd, Paul Ananth Tambyah ${ }^{3}$, MD
}

INTRODUCTION Medical school fees are rising globally. Student debt and financial background may affect residency choices, but few studies have been conducted in Asia. This study aimed to explore the relationship between financial background, student debt and postgraduate residency choices among medical students in Singapore.

METHODS An anonymised survey of all medical students in Singapore was conducted and had a response rate of $67.9 \%$. RESULTS $40.5 \%$ of our study population would graduate with debt. Medical students with monthly per capita household income < SGD 1,000 were more likely to graduate with debt (unadjusted odds ratio [OR] 2.0,95\% confidence interval [Cl] 1.6-2.7; $\mathrm{p}<0.001$ ) and feel burdened by the cost of medical education (unadjusted OR 2.8, 95\% $\mathrm{Cl} 2.0-3.9 ; \mathrm{p}<0.001$ ). Students with monthly per capita household income < SGD 1,000 (unadjusted OR 1.818, 95\% Cl 1.338-2.470, p<0.001; adjusted OR 1.692, 95\% Cl 1.202-2.381, $\mathrm{p}=0.003$ ) and those with debt (unadjusted OR 1.623, 95\% Cl 1.261-2.090, $\mathrm{p}<0.001$; adjusted OR 1.393, 95\% Cl 1.048-1.851, $\mathrm{p}=0.022$ ) were more likely to rank at least one economic factor as 'very significant' in influencing their postgraduate training choices.

CONCLUSION It is concerning that despite financial aid schemes, the cost of medical education remains a burden to students from lower-income households in Singapore. Student debt and financial background may distort postgraduate career choices, creating an undue push towards high-paying specialties.

Keywords: medical education, residency selection, student debt

\section{INTRODUCTION}

Rising medical school fees and medical student debt are a global issue. More than $80 \%$ of medical students in the United States graduate with debt, owing a median amount of USD 183,000, , $^{(1)}$ which is double that of 20 years ago. Several studies from North America, Australasia and Europe have found a relationship between student debt and postgraduate residency choices, with heavily indebted students being more likely to choose high-paying non-primary care specialties ${ }^{(2)}$ and less likely to choose primary care as an option. In addition, there are suggestions that students from higher socioeconomic backgrounds were more likely to show interest in specialty careers that would allow them to afford a lifestyle similar to that in which they were raised. ${ }^{(3,4)}$ However, the interaction between student debt and postgraduate residency choices is likely to be complex, as other studies demonstrate no association between debt and the likelihood of choosing primary care. ${ }^{(3)}$ Non-financial factors, such as student demographics and medical school exposures, also heavily influence residency choices. To the best of our knowledge, very few such studies have been carried out in Asian contexts.

Singapore has three medical schools - two offering five-year undergraduate courses (Yong Loo Lin School of Medicine, National University of Singapore [NUS Medicine], and Lee Kong Chian School of Medicine [LKCMedicine], a collaboration between
Imperial College London and Nanyang Technological University [NTU]) and one offering a four-year postgraduate degree (DukeNUS Medical School). Although fees are subsidised in exchange for a compulsory five-year service bond, there have been concerns about the high and fast-rising medical school fees payable by students. Tuition fees for a medical degree range from SGD 127,000-172,200 for a Singaporean citizen (after government subsidy) over $4-5$ years, ${ }^{(5-7)}$ which is in contrast to most other NUS graduates, who pay a total of SGD 31,800 for a four-year degree..$^{(6)}$ An earlier study from Singapore showed that medical students were more likely to come from a higher socioeconomic stratum, as compared to the general population. ${ }^{(8)}$ In the last ten years, medical school fees in Singapore have risen by more than $50 \%$, with more students coming from both the lower- and higher-income segments, while fewer students came from the middle-income segment. ${ }^{(9)}$

As in the United States, careers in surgical specialties are financially more rewarding than in primary care or internal medicine; 2015 Singapore postgraduate residency match data showed 6-10 graduating senior applicants per training position in high-paying specialties (in the local context, these are procedural disciplines, e.g. ophthalmology, orthopaedics and general surgery) in stark contrast to the 1.2-1.5 graduating senior applicants per training position in family medicine, internal medicine or emergency medicine. ${ }^{(10)}$

${ }^{1}$ Division of Medicine, Singapore General Hospital, ${ }^{2}$ Department of Medicine, Tan Tock Seng Hospital, ${ }^{3}$ Department of Medicine, NUS Yong Loo Lin School of Medicine, National University of Singapore, Singapore, ${ }^{4}$ Baylor Scott and White Research Institute, Texas, USA

Correspondence: Dr Fong Jie Ming Nigel, Resident, Division of Medicine, Singapore General Hospital, Outram Road, Singapore 169608. nigelfong@gmail.com 
This study aimed to explore the relationship between financial background, student debt and postgraduate residency choices among medical students in Singapore.

\section{METHODS}

An anonymised survey was conducted among all medical students during academic year 2014/2015 (August 2014-June 2015) across all three medical schools in Singapore. The study received approval from the institutional review boards (IRBs) of both NUS (NUS IRB-13-533) and NTU (NTU IRB-2014-07-015). A participant information sheet was provided but no signed consent form was collected. At no point were participants asked to reveal names or other identifiable information, and only anonymised data was collected.

Survey participants were asked to indicate their monthly total and per capita household income (defined as total monthly household income divided by the number of people staying at the same address) and were stratified into lower income (total $<$ SGD 3,000 or per capita < SGD 1,000) and higher income (total $\geq$ SGD 3,000 or per capita $\geq$ SGD 1,000) groups. Participants were asked about financial assistance received and expected student debt on graduation. Participants also reported how much various economic and non-economic factors influenced their residency choices ('very significant', 'somewhat significant' or 'not significant'): economic factors included potential future earnings, training fee payable and length of training, while non-economic factors included interest in the specialty, work-life balance and work culture in the specialty. Finally, participants were asked to agree or disagree with the qualitative statement 'The cost of medical education is a significant burden on my family'.

Statistical analysis was performed using IBM SPSS Statistics version 22 (IBM Corp, Armonk, NY, USA). Chi-square tests were used to compare proportions and $p<0.05$ was considered to be statistically significant. Multivariate logistic regression analysis was then conducted for the outcome of a respondent who considered at least one economic factor 'very significant', including the variables with $p<0.05$ on bivariate analysis. Potential collinearity and interaction were tested for the variables included in the final model. Hosmer-Lemeshow test was conducted to assess goodness-of-fit.

\section{RESULTS}

Overall, 1,241 of 1,829 medical students responded to the survey, with an average response rate of $67.9 \%$. Responses were received from $956(66.2 \%)$ of 1,445 NUS Medicine students, 156 (61.9\%) of 252 Duke-NUS students and 129 (97.7\%) of 132 LKCMedicine students. Median monthly total household income was in the SGD 7,000-10,000 bracket and median monthly per capita household income was in the SGD 1,500-2,000 bracket. Respondents' household income distribution relative to that of the Singapore general population is displayed in Fig. 1. In total, $25.7 \%$ of students $(\mathrm{n}=319)$ across all three schools received some form of financial aid (Table I).

In our study, $448(40.5 \%)$ of 1,105 respondents reported that they would graduate with student debt; 282 (25.5\%) would owe $\geq$ SGD 100,000 ( USD 70,000) upon graduation (Table II). Respondents with monthly per capita household income $<$ SGD 1,000 were more likely to graduate with student debt (unadjusted odds ratio $[\mathrm{OR}] 2.0,95 \%$ confidence interval [Cl] 1.6-2.7; $\mathrm{p}<0.001$ ), including debt $\geq$ SGD 100,000 (unadjusted OR 1.7, 95\% Cl 1.3-2.3; $\mathrm{p}<0.001)$. ${ }^{(11)}$

$791(70.9 \%)$ of 1,115 respondents felt that the cost of medical education was a significant burden to their families. This sentiment was more marked among respondents with monthly per capita household income < SGD 1,000 (unadjusted OR 2.8, 95\% Cl 2.0-3.9; $\mathrm{p}<0.001)$ and those with student debt (unadjusted OR 3.8, 95\% Cl 2.9-5.1; $\mathrm{p}<0.001$ ). 352 (31.2\%) of 1,129 respondents found at least one economic factor to be 'very significant' in influencing residency choices. In contrast, 1,037 $(91.9 \%)$ of 1,129 respondents found at least one non-economic factor to be 'very significant'.

On univariate analysis, variables that made a respondent more likely to consider at least one economic factor as 'very significant' for residency choices were: per capita household income $<$ SGD 1,000 (unadjusted OR 1.818, 95\% Cl 1.338-2.470; $\mathrm{p}<0.001$ ), presence of student debt (unadjusted OR $1.623,95 \% \mathrm{Cl} 1.261-$ 2.090; $\mathrm{p}<0.001$ ), being a postgraduate (unadjusted OR 2.431, $95 \% \mathrm{Cl} 1.722-3.433 ; \mathrm{p}<0.001$ ), being an international student (unadjusted OR 1.685, 95\% Cl 1.020-2.783; $p=0.042$ ) and being in the preclinical years of medical school (unadjusted OR 2.090, 95\% Cl 1.622-2.692; p < 0.001) (Table III). Whether a respondent worked part-time was not found to be statistically significant $(p=0.557)$.

Multivariate logistic regression analysis was performed for all variables analysed during univariate analysis, except whether a respondent worked part-time, which was not found to be statistically significant on univariate analysis (Table III). Both the presence of student debt (adjusted OR 1.393, $95 \% \mathrm{Cl} 1.048-1.851 ; p=0.022$ ) and monthly per capita household income < SGD 1,000 (adjusted OR 1.692, 95\% Cl 1.202-2.381; $p=0.003$ ) remained independent predictors of a respondent considering at least one economic factor to be 'very significant'. Similarly, being a postgraduate (adjusted OR 1.686, $95 \% \mathrm{Cl} 1.068-2.661 ; \mathrm{p}=0.025)$ and being in the preclinical years (adjusted OR 1.690, 95\% Cl 1.277-2.232; p < 0.001) remained significant. Whether the respondent was a local or international student did not reach statistical significance $(p=0.347)$. There was no significant collinearity (variance inflation factor range 1.03-1.21) between these variables, and no interaction was noted.

\section{DISCUSSION}

The cost of medical education appears to be a significant financial burden across all socioeconomic strata for Singapore medical students, as in other parts of the world. However, only $40.5 \%$ of our study population would graduate with student debt, which is half of the $81 \%$ seen in the United States. ${ }^{(1)}$ This may reflect an Asian context, where it is common for parents to fully sponsor their children's university education (at times tapping into their retirement savings or selling their assets to do so), especially when undergraduate medical schools are much more common 

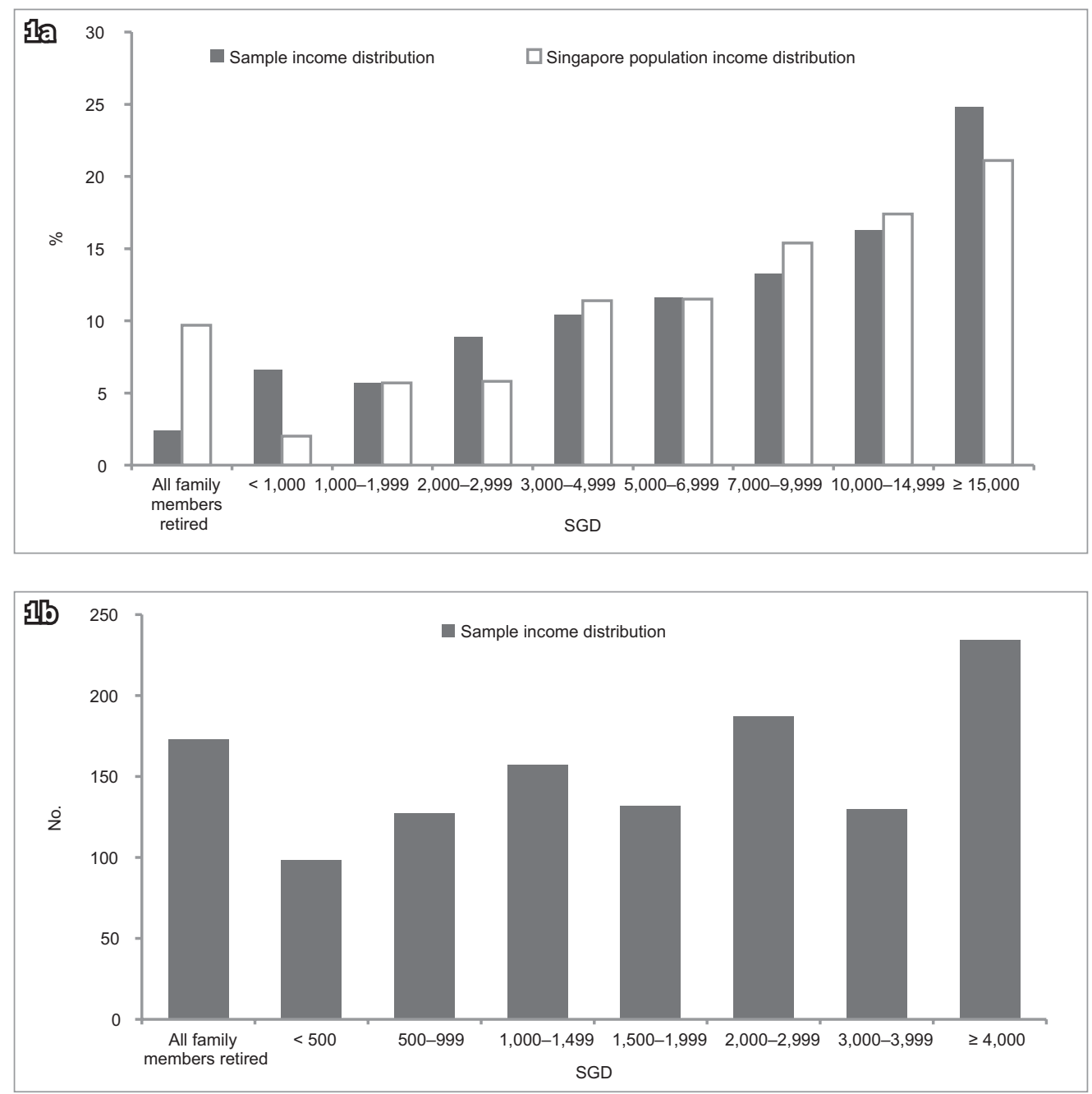

Fig. 1 Charts show (a) total household income distribution (in SGD) of all respondents and the Singapore general population (income distribution data was sourced from the Department of Statistics, Singapore ${ }^{(13)}$ ); and (b) per capita household income distribution (in SGD) of all respondents.

than postgraduate medical schools and are generally associated with lower fees.

It is concerning, but not surprising, that students from lowerincome households (per capita household income < SGD 1,000, or approximately USD 700) were more likely to feel that the cost of medical education was a significant burden to their families and were more likely to go into debt to finance their medical education, in spite of financial aid being available. We already see a smaller proportion of medical students coming from lowerincome backgrounds. ${ }^{(8)}$ It would be undesirable and unjust for medical schools to be restricted to the well-to-do, and steps need to be taken to ensure that the available financial aid goes to those who need it the most.

In terms of residency choices, we found that non-economic considerations (e.g. interest in the specialty, work-life balance and work culture) were on balance more important than economic factors across the income groups, which is reassuring. Nonetheless, we still note that high-paying specialties have a far higher ratio of applicants to places available than other specialties, such as family medicine, internal medicine or emergency medicine. Students with debt were more likely to find economic factors to be of greater importance. This is expected, given that debt repayments in the local context begin on graduation and cannot be deferred until completing postgraduate residency training. ${ }^{(12)}$ These can be a significant burden in the initial years of postgraduate medical training. Students from lower-income households (per capita household income < SGD 1,000) were also more likely to consider economic factors more significant when making residency choices, and this was independent of the effect of debt. Students from a lower-income background likely wanted to escape the lower socioeconomic stratum. Therefore, student debt and financial background may be driving factors behind the popularity of high-paying specialties and may distort residency choices. This is not ideal, as the choice of postgraduate training should be primarily based on interest and aptitude rather than financial concerns.

This study is the first of its kind in an Asian context, comprehensively covering all medical students in Singapore. Our study had several limitations. Firstly, we used student-reported assessments of the significance of three economic and three noneconomic factors to draw conclusions about how student debt and financial background affected residency choices. This may not accurately reflect actual residency applications and the future career trajectories of our respondents. A follow-up study on a cohort 
Table I. Household income and financial aid demographics of survey respondents.

\begin{tabular}{|c|c|c|c|c|c|c|}
\hline \multirow[t]{3}{*}{ Variable } & \multicolumn{6}{|c|}{ No. (\%) } \\
\hline & \multicolumn{2}{|c|}{ NUS Medicine ( $n=956)$} & \multicolumn{2}{|c|}{ LKCMedicine $(n=129)$} & \multicolumn{2}{|c|}{ Duke-NUS $(n=156)$} \\
\hline & Total & Receiving aid & Total & Receiving aid & Total & Receiving aid \\
\hline \multicolumn{7}{|l|}{ Monthly total household income* } \\
\hline$<$ SGD 3,000 & 182 & $61(33.5)$ & 8 & $6(75.0)$ & 73 & $57(78.1)$ \\
\hline$\geq \operatorname{SGD} 3,000$ & 751 & $119(15.8)$ & 118 & $27(22.9)$ & 79 & $49(62.0)$ \\
\hline \multicolumn{7}{|c|}{ Monthly per capita household income* } \\
\hline$<$ SGD 1,000 & 223 & $79(35.4)$ & 10 & $7(70.0)$ & 85 & $66(77.6)$ \\
\hline$\geq \operatorname{SGD} 1,000$ & 643 & $66(10.3)$ & 111 & $23(20.7)$ & 57 & $31(54.4)$ \\
\hline All household members retired & 23 & $1(4.3)$ & 3 & $1(33.3)$ & 4 & $1(25.0)$ \\
\hline
\end{tabular}

Respondents whose household members had all retired were excluded from analysis. *Data was missing for 67 NUS Medicine students, 5 LKCMedicine students and 10 Duke-NUS students. Duke-NUS: Duke-NUS Medical School; LKCMedicine: Lee Kong Chian School of Medicine; NUS Medicine: Yong Loo Lin School of Medicine, National University of Singapore

Table II. Relationship between monthly per capita household income and student debt.

\begin{tabular}{|llll|}
\hline Student debt & \multicolumn{2}{c|}{ Per capita household income* } & p-value \\
\cline { 2 - 4 } & < SGD 1,000 (n= 315) & $\geq$ SGD 1,000 $(\mathbf{n}=\mathbf{7 9 0})$ & Total $(\mathbf{n}=\mathbf{1 , 1 0 5 )}$ \\
\hline None & $148(47.0)$ & $509(64.4)$ & $657(59.5)$ \\
\hline Any debt & $167(53.0)$ & $281(35.6)$ & $448(40.5)$ \\
\hline SGD 1-24,999 & $7(2.2)$ & $6(0.8)$ & $13(1.2)$ \\
\hline SGD 25,000-49,999 & $7(2.2)$ & $11(1.4)$ & $18(1.6)$ \\
\hline SGD 50,000-74,999 & $17(5.4)$ & $15(1.9)$ & $32(2.9)$ \\
\hline SGD 75,000-99,999 & $32(10.2)$ & $71(9.0)$ & $103(9.3)$ \\
\hline$\geq$ SGD 100,000 & $104(33.0)$ & $178(22.5)$ & $282(25.5)$ \\
\hline
\end{tabular}

*Data presented as no. (\%). Respondents whose household members had all retired and 24 respondents who did not have matching data points for debt were excluded from analysis.

Table III. Variables affecting the significance of economic factors on residency choices (at least one economic factor rated as very significant).

\begin{tabular}{|c|c|c|c|c|}
\hline \multirow[t]{2}{*}{ Variable } & \multicolumn{2}{|c|}{ Univariate } & \multicolumn{2}{|c|}{ Multivariate } \\
\hline & Unadjusted OR (95\% Cl) & p-value & Adjusted OR (95\% CI) & p-value \\
\hline \multicolumn{5}{|c|}{ Per capita household income* } \\
\hline$<$ SGD 1,000 & $1.818(1.338-2.470)$ & $<0.001$ & $1.692(1.202-2.381)$ & 0.003 \\
\hline$\geq \operatorname{SGD} 1,000$ & Ref & & Ref & \\
\hline \multicolumn{5}{|l|}{ Student debt } \\
\hline Yes & $1.623(1.261-2.090)$ & $<0.001$ & $1.393(1.048-1.851)$ & 0.022 \\
\hline No & Ref & & Ref & \\
\hline \multicolumn{5}{|l|}{ Medical course } \\
\hline Postgraduate & $2.431(1.722-3.433)$ & $<0.001$ & $1.686(1.068-2.661)$ & 0.025 \\
\hline Undergraduate & Ref & & Ref & \\
\hline \multicolumn{5}{|c|}{ International student } \\
\hline Yes & $1.685(1.020-2.783)$ & 0.042 & $0.736(0.389-1.394)$ & 0.347 \\
\hline No & Ref & & Ref & \\
\hline \multicolumn{5}{|c|}{ Stage of medical education } \\
\hline Preclinical & $2.090(1.622-2.692)$ & $<0.001$ & $1.690(1.277-2.232)$ & $<0.001$ \\
\hline Clinical & Ref & & Ref & \\
\hline \multicolumn{5}{|l|}{ Part-time work } \\
\hline Yes & $1.118(0.766-1.631)$ & 0.557 & - & - \\
\hline No & $\mathrm{R}$ & & - & \\
\hline
\end{tabular}

*Respondents whose household members had all retired were excluded from analysis. Cl: confidence interval; OR: odds ratio; Ref: Reference 
of medical graduates (including residents and non-residents) would help to more accurately capture the effect of financial background, student debt and other factors on eventual career paths. Secondly, financial information was self-reported and not verifiable. Thirdly, we used monthly per capita household income from work as a general indicator of student financial background without taking into account other factors, such as investment income or expenditure on the care of disabled family members. Financial status is certainly more complex than can be captured in a single statistic. However, we were limited by the amount of data available.

In summary, we found that many medical students in Singapore, like their counterparts in North America, faced a significant debt burden upon graduation. This has a significant impact on postgraduate residency choices, especially for students from the lower-income groups. Measures should be taken to ensure that our medical graduates are appropriately placed in their chosen vocations without undue financial concerns affecting their career paths. This would also help to ensure the best possible care for their future patients.

\section{ACKNOWLEDGEMENTS}

The authors would like to thank Singapore Medical Association (SMA), NUS Medicine, Duke-NUS Medical School and LKCMedicine for their unwavering support for this study. We would especially like to thank A/Prof Hooi Shing Chuan (Vice Dean, NUS Medicine), A/Prof Chin Jing Jih (Assistant Dean, LKCMedicine), Dr Mara McAdams (Assistant Dean, DukeNUS), Mr Martin Ho (Chief Administrator, SMA), as well as Mr Koh Hwei Keong, Ms Yap Pek Be and Ms Salbiah Binte Amin (NUS Medicine) for their guidance and administrative support throughout the study.

\section{REFERENCES}

1. Association of American Medical Colleges. Medical Student Education: Debt, Costs, and Loan Repayment Fact Card 2015. Available at: http://members. aamc.org/eweb/upload/2015\%20Debt\%20Fact\%20Card.pdf. Accessed March 1, 2016.

2. Grayson MS, Newton DA, Thompson LF. Payback time: the associations of debt and income with medical student career choice. Med Educ 2012; 46:983-91.

3. Phillips RL Jr, Dodoo MS, Petterson S, et al. Specialty and Geographic Distribution of the Physician Workforce: What Influences Medical Student and Resident Choices? Michigan: The Robert Graham Center: Policy Studies in Family Medicine and Primary Care, 2009.

4. Senf JH, Campos-Outcalt D, Kutob R. Factors related to the choice of family medicine: a reassessment and literature review. J Am Board Fam Pract 2003; 16:502-12.

5. Duke-NUS Medical School, Singapore. Tuition fees, scholarships and financial aid. Available at: https://www.duke-nus.edu.sg/admissions/tuition-feesscholarships-financial-aid. Accessed March 1, 2016.

6. National University of Singapore, Singapore. Fees for Undergraduate Programmes. Available at: http://www.nus.edu.sg/registrar/edu/UG/fees.html. Accessed March 1, 2016.

7. Nanyang Technological University. Tuition Fees for AY2015-16 Freshmen. Available at: http://www3.ntu.edu.sg/oad2/GA_R/AY2015-2016\%20 Research\%20Fees_Final.pdf. Accessed March 1, 2016.

8. $\mathrm{Ng} \mathrm{CL}$, Tambyah PA, Wong CY. Cost of medical education, financial assistance and medical school demographics in Singapore. Singapore Med J 2009; 50:462-7.

9. Sayampanathan AA, Tan WT, Fong JM, et al. An update on finances and financial support for medical students in the Yong Loo Lin School of Medicine. Singapore Med J 2017; 58:206-11.

10. Ministry of Health Holdings, Singapore. 2015 Residency Match Results. Available at: http://www.physician.mohh.com.sg/residency/downloads/2015_ Match_Results.pdf. Accessed February 1, 2016.

11. Szumilas M. Explaining odds ratios. J Can Acad Child Adolesc Psychiatry 2010; 19:227-9.

12. Development Bank of Singapore, Singapore. Education loans: tuition fee loan. Available at: http://www.dbs.com.sg/personal/loans/education-loans/tuitionfee-loan. Accessed March 1, 2016.

13. Department of Statistics, Singapore. Key Household Income Trends, 2015. Available at: http://www.singstat.gov.sg/docs/default-source/default-documentlibrary/publications/publications_and_papers/household_income_and_ expenditure/pp-s22.pdf. Accessed March 1, 2016. 